\title{
Quercetin enhances the effects of 5-fluorouracil-mediated growth inhibition and apoptosis of esophageal cancer cells by inhibiting NF-кB
}

\author{
LU CHUANG-XIN, WANG WEN-YU, CUI YAO, LI XIAO-YAN and ZHOU YUN
}

Department of Oncology, Henan People's Hospital of Zhengzhou University, Zhengzhou, Henan 450003, P.R. China

Received April 25, 2012; Accepted July 19, 2012

DOI: $10.3892 / 01.2012 .829$

\begin{abstract}
Despite its limited success, 5-fluorouracil (5-FU) remains the primary chemotherapy agent for the treatment of esophageal cancer. Quercetin has been demonstrated to inhibit the growth of transformed cells. The present study was conducted to examine whether quercetin combined with conventional chemotherapeutic agents would improve the therapeutic strategy for esophageal cancer. In this study, an MTT assay was used to determine the effects of quercetin on the proliferation of EC9706 and Eca109 cells. Annexin V-FITC/propidium iodide (PI)-stained fluorescence-activated cell sorter (FACS) analysis was used to detect the apoptotic fraction of treated cells, and western blot analysis was used to examine the protein levels. The results of our study demonstrated that quercetin in combination with 5-FU significantly inhibited growth $(\mathrm{P}<0.05)$ and stimulated apoptosis $(\mathrm{P}<0.005)$ in EC9706 and Eca109 esophageal cancer cells compared with quercetin or 5-FU alone. These changes were associated with the decreased expression of a phosphorylated inhibitory molecule of $\mathrm{NF}-\kappa \mathrm{B}$ $(\mathrm{pI} \kappa \mathrm{B} \alpha)$, which was activated by exposure to 5 -FU alone. We suggest that inclusion of quercetin to the conventional chemotherapeutic agent 5-FU may be an effective therapeutic strategy for esophageal cancer.
\end{abstract}

\section{Introduction}

Esophageal cancer is a highly aggressive malignant disease, which is generally diagnosed at an advanced stage. Esophageal cancer has an extremely poor prognosis with a 5-year survival rate of less than $10 \%$ (1), and current chemotherapy treatments often have limited success and fatal outcomes. Efforts are being made to improve the chemotherapeutic interventions for metastatic esophageal cancer. A number of esophageal

Correspondence to: Professor Zhou Yun, Department of Oncology, Henan People's Hospital of Zhengzhou University, Zhengzhou, Henan 450003, P.R. China

E-mail: syzlk2010@yahoo.com.cn

Key words: quercetin, 5-fluorouracil, esophageal cancer, NF-кB tumors develop resistance to chemotherapy during the course of therapy. This drug resistance often results in additional toxicities, of which some are fatal, and are the major cause of treatment failure $(2,3)$. Therefore, numerous studies have focused on the molecular mechanisms of chemotherapy resistance to determine more effective methods for overcoming this resistance.

5-Fluorouracil (5-FU) remains the most effective chemotherapeutic option available for the treatment of advanced esophageal cancer. In numerous patients, esophageal tumors are either inherently resistant to chemotherapy, or the tumors develop resistance during treatment when 5-FU is administered alone or in conjunction with other agents (4). The ability to inhibit apoptosis appears to be the principal mechanism by which resistant cancer cells are protected from chemotherapy and radiation (5-7). The cellular mechanisms that protect cancer cells from apoptosis are complex $(8,9)$. The inducible activation of the nuclear transcription factor $\mathrm{NF}-\kappa \mathrm{B}$ has been identified to inhibit the apoptotic response to chemotherapy and radiation (10). Previous studies have demonstrated that treatment with chemotherapy drugs activates NF- $\mathrm{B}$, and inhibition of NF- $\mathrm{KB}$ enhances the cytotoxic effect of drugs in cancer cells $(11,12)$.

Quercetin, the major constituent of the flavonol subclass of flavonoids (13), has been identified to induce apoptosis in a number of tumor cell lines (14) and interact with a broad range of enzymes, including receptor kinases $(15,16)$. We propose that $\mathrm{NF}-\kappa \mathrm{B}$ plays a central role in the chemoresistance of esophageal cancer cells treated with 5-FU. To study the molecular mechanisms involved in the anticancer effects of quercetin on esophageal cancer, we focused our attention on the effects of quercetin on the chemosensitivity of human esophageal carcinoma cells.

\section{Materials and methods}

Human cells and culture. Human esophageal cancer cells (EC9706 and Eca109) were cultured in RPMI-1640 medium supplemented with heat inactivated $10 \%$ fetal bovine serum (FBS), $100 \mathrm{U} / \mathrm{ml}$ penicillin and $100 \mathrm{mg} / \mathrm{ml}$ streptomycin. Cell lines were maintained in a humidified incubator containing $5 \% \mathrm{CO}_{2}$ at $37^{\circ} \mathrm{C}$. The cells were passaged twice a week at an initial density of $1 \times 10^{6}$ cells $/ \mathrm{ml}$. 
3-(4,5-dimethylthiazol-2-yl)-2,5-diphenyltetrazolium bromide (MTT) assay. An MTT assay was conducted according to the method described by Kawada et al (17). A $150 \mu \mathrm{l}$ aliquot of $1 \times 10^{5}$ cells suspended in RPMI-1640 medium supplemented with $10 \%$ FBS was added to each well of a 96-well microtiter plate. The cells were cultured in the absence (control) or presence of various agents, and the plates were incubated at $37^{\circ} \mathrm{C}$ in a humidified incubator containing $5 \% \mathrm{CO}_{2}$ for $48 \mathrm{~h}$. Following this, $20 \mu \mathrm{l}$ of the MTT reagent $(5 \mathrm{mg} / \mathrm{ml})$ was added to each well, and the cells were allowed to incubate for $4 \mathrm{~h}$. A total of $150 \mu \mathrm{l}$ of dimethyl sulfoxide (DMSO) was added to each well in order to dissolve the formazan crystal that had formed, and the optical density (OD) was recorded at $490 \mathrm{~nm}$. The growth inhibition rate was expressed as: Growth inhibition $(\%)=(1-\mathrm{OD}$ of treated $/ \mathrm{OD}$ of control $) \times 100$.

Annexin V-FITC/propidium iodide (PI)-stained fluorescence-activated cell sorting (FACS). The cells were harvested by trypsinization and washed twice with cold PBS. Once the cells had been centrifuged at $1,000 \mathrm{x}$ g for $5 \mathrm{~min}$, the supernatant was discarded and the pellet was resuspended in binding buffer at a density of $1.0 \times 10^{5}-1.0 \times 10^{6}$ cells $/ \mathrm{ml}$. Following this, $100 \mu$ l of the sample solution was transferred to a $5-\mathrm{ml}$ culture tube and incubated with $5 \mu 1$ of FITC-conjugated Annexin $\mathrm{V}$ and $5 \mu \mathrm{l}$ of PI for $15 \mathrm{~min}$ at room temperature in the dark. Subsequently, $400 \mu \mathrm{l}$ of binding buffer was added to each sample and the samples were analyzed by FACS using CellQuest Research Software (Largo, FL, USA).

Western blot analysis. EC9706 and Eca109 cells were collected following centrifugation at $500 \mathrm{xg}$ for $5 \mathrm{~min}$, and the pellets were resuspended in lysis buffer containing $1 \%$ NP40, $1 \mathrm{mM}$ phenylmethylsulfonyl fluoride, $40 \mathrm{mM}$ Tris- $\mathrm{HCl}$ (pH 8.0), $150 \mathrm{mM} \mathrm{NaCl}$ and $1 \mathrm{mM} \mathrm{NaOH}$ at $4^{\circ} \mathrm{C}$ for $15 \mathrm{~min}$. Cell lysates were resolved on $12.5 \%$ SDS-polyacrylamide gels and transferred to nitrocellulose membranes according to the manufacturer's instructions. Antibody binding was detected using an enhanced chemiluminescence kit (ECL) with a hyper-ECL film. The antibodies against $\mathrm{pI \kappa B} \alpha$ and $\beta$-actin were purchased from Santa Cruz Biotechnology, Inc. (Santa Cruz, CA, USA).

Statistical analysis. The values shown are the mean \pm standard error of mean (SEM). Statistical analyses were conducted using the Student's t-test and one-way ANOVA. $\mathrm{P}<0.05$ was considered to indicate a statistically significant difference and statistical calculations were conducted using SPSS version 13.0 software (SPSS, Inc., Chicago, IL, USA).

\section{Results}

Effects of quercetin on the proliferation and viability of EC9706 and Ecal09 cell lines. A dose-response study was conducted for EC9706 and Eca109 cancer cells in response to quercetin. Quercetin inhibited the growth of both cell lines in a dose-dependent manner, revealing a maximum inhibition of $60 \%$ at $100-200 \mu \mathrm{M}$ concentrations (Fig. 1). A 50-60\% growth inhibition was observed in both cell lines at a concentration of $100 \mu \mathrm{M}$, which was then used in subsequent studies (Fig. 1). Similarly, 5-FU also inhibited the growth of the EC9706 and

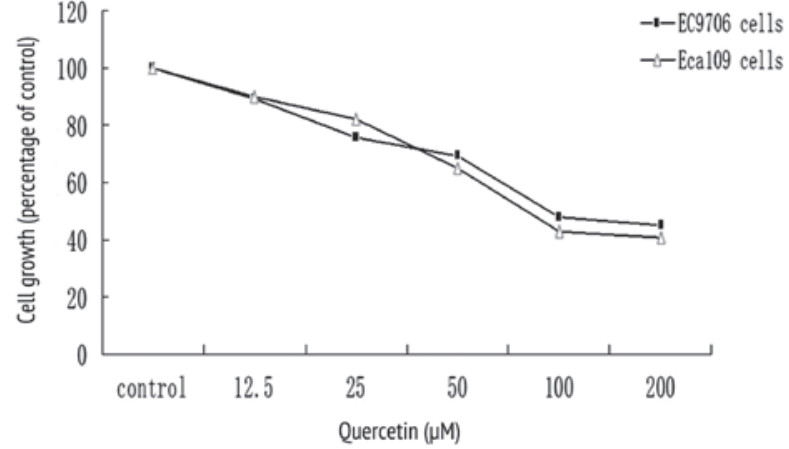

Figure 1. Dose-dependant inhibition of growth (as determined by an MTT assay) of esophageal cancer cells EC9706 and Eca109 in response to quercetin. The cells were incubated for $48 \mathrm{~h}$ in the absence (control) or presence of quercetin. MTT, 3-(4,5-dimethylthiazol-2-yl)-2,5-diphenyltetrazolium bromide.
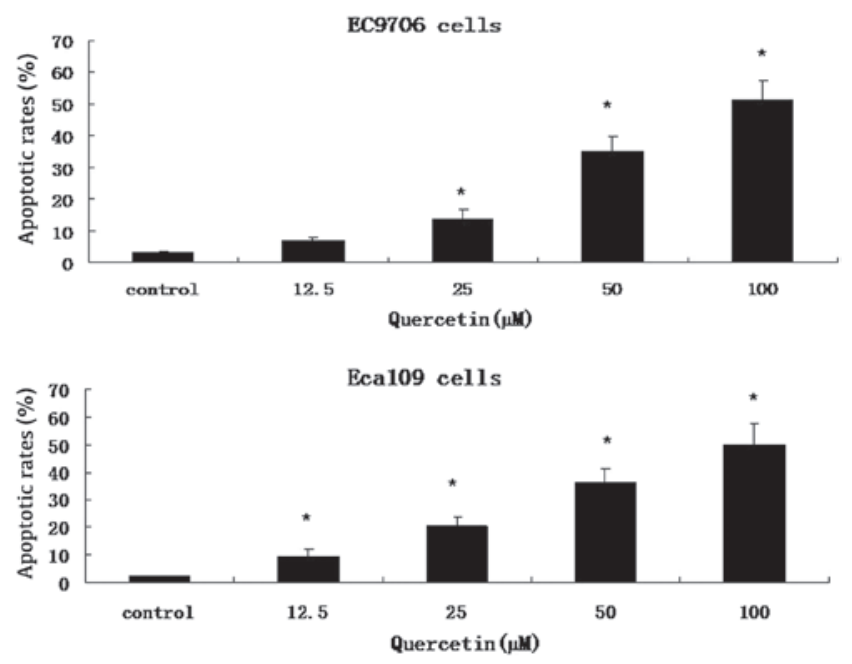

Figure 2. Dose-dependant apoptosis at $48 \mathrm{~h}$ in EC9706 and Eca109 cells with quercetin. The values represented are the mean \pm SEM of 3-4 replicates. *A statistically significant value compared with the control group $(\mathrm{P}<0.05)$. SEM, standard error of mean.

Eca109 esophageal cancer cells (data not shown). 5-FU was used at a concentration of $0.2 \mathrm{mM}$ in subsequent experiments.

Annexin V-FITC/PI-stained FACS analysis. Cells were stained with Annexin V-FITC and PI. A FACS analysis was conducted to distinguish and quantify the percentage of viable and apoptotic cells following treatment with $0.2 \mathrm{mM} \mathrm{5-FU,} 100 \mu \mathrm{M}$ quercetin or a combination of both drugs, for $48 \mathrm{~h}$. Quercetin demonstrated a dose-dependent increase in apoptosis in EC9706 and Eca109 cells (Fig. 2). In the combinatorial treatment group, there was a greater degree of apoptosis compared to that is the agent alone or control groups (Fig. 3).

Inhibition of NF- $\kappa B$ by quercetin enhances 5-FU-induced apoptosis in esophageal cancer cells. To investigate whether the effect of quercetin on EC9706 and Eca109 cells was mediated through the NF- $\mathrm{kB}$ signaling pathway, we examined the effects of $50 \mu \mathrm{M}$ quercetin and $0.2 \mathrm{mM} 5$-FU on the expression levels of a phosphorylated inhibitory molecule of NF- $\mathrm{KB}$ 

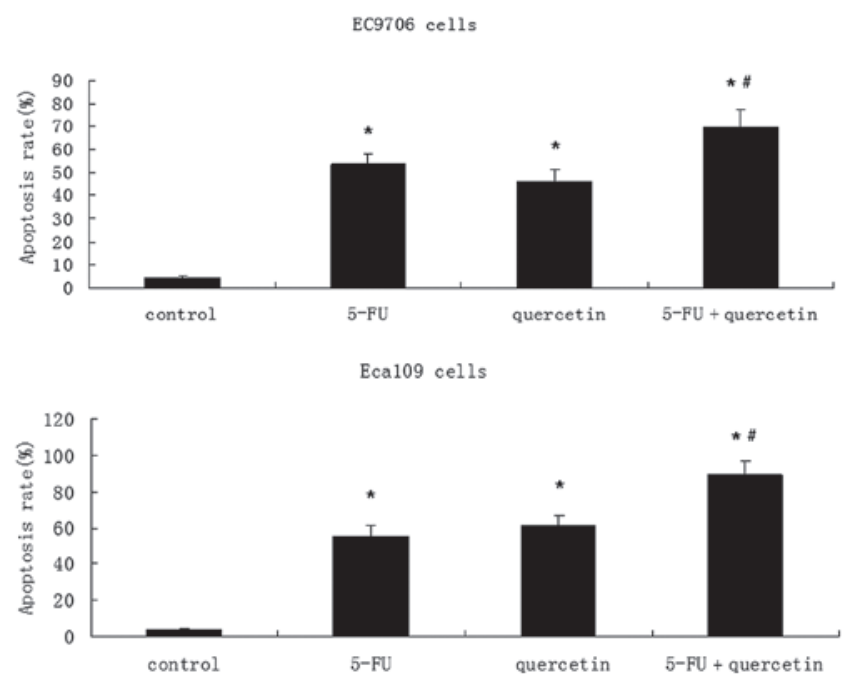

Figure 3. Apoptosis induction at $48 \mathrm{~h}$ in EC9706 and Eca109 cells with $100 \mu \mathrm{M}$ quercetin, $0.2 \mathrm{mM} 5$-FU or $0.1 \mathrm{mM} 5$-FU $+50 \mu \mathrm{M}$ quercetin. The values represent the mean \pm SEM of 3-4 replicates. ${ }^{*}$ A statistically significant value compared with the control group $(\mathrm{P}<0.05)$; ${ }^{~} \mathrm{~A}$ statistically significant value compared with the $5-\mathrm{FU}$ or quercetin only groups $(\mathrm{P}<0.05) .5-\mathrm{FU}$, 5 -fluorouracil; SEM, standard error of mean.

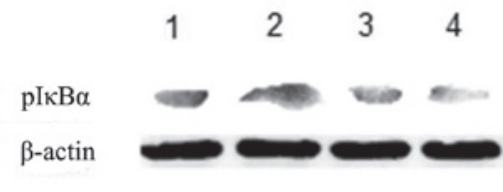

EC9706 cells

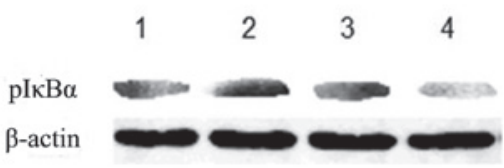

Eca109 cells

Figure 4. Western blot analysis of EC9706 and Eca109 cells. Lane 1, control; lane 2, 5-FU; lane 3, 5-FU + quercetin; lane 4, quercetin. Phosphorylated $\mathrm{I} \kappa \mathrm{B} \alpha$ is increased in the presence of 5-FU and decreased in the presence of quercetin. $\beta$-actin expression was used as a loading control. 5-FU, 5-fluorouracil; I $\mathrm{B} \alpha$, an inhibitory molecule of $\mathrm{NF}-\kappa \mathrm{B}$.

( $\mathrm{pI} \kappa \mathrm{B} \alpha$ ) using western blot analysis. As shown in Fig. 4, quercetin significantly suppressed the expression levels of $\mathrm{pI} \kappa \mathrm{B} \alpha$ $24 \mathrm{~h}$ following drug treatment.

\section{Discussion}

It has been well established that the reduced capacity of tumor cells to undergo apoptotic cell death plays a key role in the pathogenesis of cancer and in therapeutic failure (18-20). Evidence suggests that chemotherapy induces apoptosis as part of its therapeutic effects and that chemoresistance is likely to involve an antiapoptotic mechanism. Tumor cells often have multiple alterations in their apoptotic signaling pathways that lead to chemotherapy failure $(21,22)$. Overriding these mutations is a significant area of focus in anticancer drug research.

$\mathrm{NF}-\kappa \mathrm{B}$ is primarily retained in the cytoplasm as an inactive complex through direct binding of $\mathrm{I} \kappa \mathrm{B}$. Recent data indicate that activation of $\mathrm{NF}-\kappa \mathrm{B}$ represents a principal pathway in inducible chemoresistance. Cell exposure to various stimuli results in the phosphorylation and degradation of $\mathrm{I} \kappa \mathrm{B} \alpha$, the translocation of active NF- $\kappa \mathrm{B}$ to the nucleus (23) and the subsequent induction of target genes that code for antiapoptotic proteins, including survivin. This gene activation leads to tumor cell resistance to cytotoxic therapy (24). NF- $\kappa \mathrm{B}$ has been identified as an antiapoptotic protein, which is activated by chemotherapy drugs (e.g., 5-FU) in a number of cancer cell lines, including esophageal cancer cells (2).

In our study, 5-FU and quercetin demonstrated a dose-dependent induction of apoptosis in addition to the inhibition of EC9706 and Eca109 cell growth. Although the anticancer effect of quercetin was mild, the addition of quercetin to 5-FU significantly enhanced the cytotoxic and apoptotic cellular responses, even at low concentrations of 5-FU. This demonstrates that these cells may be more sensitive to $5-\mathrm{FU}$ when combined with quercetin.

Based on studies suggesting that $\mathrm{NF}-\kappa \mathrm{B}$ is constitutively active in a number of cancer cell lines (25-27), we investigated whether NF- $\mathrm{KB}$ was involved in the apoptotic process induced by 5-FU in EC9706 and Eca109 cells. Our results indicate that $5-\mathrm{FU}$ mediates the activation of $\mathrm{NF}-\kappa \mathrm{B}$ through the phosphorylation of the I $\kappa \mathrm{B} \alpha$ protein, leading to increased expression levels of $\mathrm{pI} \kappa \mathrm{B} \alpha$. When the increase in $\mathrm{pI} \kappa \mathrm{B} \alpha$ reaches a maximal value at a certain concentration of 5-FU, further dose increases of the chemotherapy drug may not be effective. Our data suggest that these cell lines may be resistant to 5-FU treatment, which has also been observed in patients who are undergoing treatment.

The last series of experiments was conducted to determine the potential mechanisms by which quercetin inhibits $\mathrm{NF}-\kappa \mathrm{B}$ activation. We revealed that the addition of quercetin significantly enhanced the cytotoxic and apoptotic responses to 5-FU. To confirm that quercetin plays a converse role in the 5-FU-mediated activation of $\mathrm{NF}-\kappa \mathrm{B}$, we sought to determine the extent to which $\mathrm{NF}-\kappa \mathrm{B}$ was affected by quercetin and 5-FU, alone or in combination. Consistent with other studies, 5-FU increased the expression of $\mathrm{pI} \kappa \mathrm{B} \alpha$ in EC9706 and Eca109 cells, but expression of $\mathrm{pI} \kappa \mathrm{B} \alpha$ was inhibited when quercetin was combined with 5-FU, although quercetin had little effect on its own.

Our data demonstrated that quercetin acts synergistically with 5-FU to induce apoptosis in esophageal cancer cells. This may be attributed to the attenuation of NF- $\kappa \mathrm{B}$ activation, as demonstrated by the decrease in $\mathrm{pI} \kappa \mathrm{B} \alpha$ expression. These data suggest that the addition of quercetin to 5-FU may potentially be a superior therapeutic strategy for the treatment of esophageal cancer.

\section{References}

1. Greenlee RT, Murray T, Bolden S and Wingo PA: Cancer Statistics. CA Cancer J Clin 50: 7-33, 2000.

2. Li J, Minnich DJ, Camp ER, Brank A, Mackay SL and Hochwald SN: Enhanced sensitivity to chemotherapy in esophageal cancer through inhibition of NF-кB. J Surg Res 132: 112-120, 2006

3. Lee CT, Seol JY, Lee SY, et al: The effect of adenovirus-Ikappa Balpha transduction on the chemosensitivity of lung cancer cell line with resistance to cis-diaminedichloroplatinum (II) (cisplatin) and doxorubicin (adriamycin). Lung Cancer 41: 199-206, 2003 
4. Shim HJ, Cho SH, Hwang JE, et al: Phase II study of docetaxe and cisplatin chemotherapy in 5-fluorouracil/cisplatin pretreated esophageal cancer. Am J Clin Oncol 33: 624-628, 2010.

5. Friesen C, Herr I, Krammer PH and Debatin KM: Involvement of the CD95 (APO-1/FAS) receptor/ligand system in drug-induced apoptosis in leukemia cells. Nat Med 2: 574-577, 1996.

6. Fulda S, Susin SA, Kroemer G and Debatin KM: Molecular ordering of apoptosis induced by anticancer drugs in neuroblastoma cells. Cancer Res 58: 4453-4460, 1998.

7. Fisher DE: Apoptosis in cancer therapy: crossing the threshold. Cell 78: 539-542, 1994.

8. Lotem J and Sachs L: Regulation by bcl-2, c-myc, and p53 of susceptibility to induction of apoptosis by heat shock and cancer chemotherapy compounds in differentiation-competent and -defective myeloid leukemic cells. Cell Growth Differ 4: 41-47, 1993.

9. Wang CY, Mayo MW, Korneluk RG, Goeddel DV and Baldwin AS Jr: NF- $\kappa$ B antiapoptosis: induction of TRAF1 and TRAF2 and c-IAP1 and c-IAP2 to suppress caspase- 8 activation. Science 281: 1680-1683, 1998.

10. Wang CY, Mayo MW and Baldwin AS Jr: TNF- and cancer therapy-induced apoptosis: potentiation by inhibition of $\mathrm{NF}-\kappa \mathrm{B}$ Science 274: 784-787, 1996.

11. Voboril R, Hochwald SN, Li J, Brank A, Weberova J, Wessels F, Moldawer LL, Camp ER and MacKay SL: Inhibition of NF-kappa B augments sensitivity to 5-fluorouracil/folinic acid in colon cancer. J Surg Res 120: 178-188, 2004.

12. Cusack JC Jr, Liu R, Houston M, et al: Enhanced chemosensitivity to CPT-11 with proteasome inhibitor PS-341: implications for systemic nuclear factor- $\kappa \mathrm{B}$ inhibition. Cancer Res 61 : 3535-3540, 2001

13. Hertog MG, Hollman PC, Katan MB and Kromhout D: Intake of potentially anticarcinogenic flavonoids and their determinants in adults in the Netherlands. Nutr Cancer 20: 21-29, 1993.

14. Csokay B, Prajda N, Weber G and Olah E: Molecular mechanisms in the antiprolife- rative action of quercetin. Life Sci 60 2157-2163, 1997

15. Casagrande F and Darbon JM: Effects of structurally related flavonoids on cell cycle progression of human melanoma cells regulation of cyclin-dependent kinases CDK2 and CDK1. Biochem Pharmacol 61: 1205-1215, 2001.
16. Nguyen TT, Tran E, Nguyen TH, Do PT, Huynh TH and Huynh H The role of activated MEK-ERK pathway in quercetin-induced growth inhibition and apoptosis in A549 lung cancer cells. Carcinogenesis 25: 647-659, 2004

17. Kawada K, Yonei T, Ueoka H, et al: Comparison of chemosensitivity tests: clonogenic assay versus MTT assay. Acta Med Okayama 56: 129-134, 2002.

18. Lam MH, Liu Q, Elledge SJ and Rosen JM: Chk1 is haploinsufficient for multiple functions critical to tumor suppression. Cancer Cell 6: 45-59, 2004

19. Yamamura Y, Lee WL, Goh MX and Ito Y: Role of TAp73alpha in induction of apoptosis by transforming growth factor-beta in gastric cancer cells. FEBS Lett 582: 2663-2667, 2008.

20. Kurokawa M, Zhao C, Reya T and Kornbluth S: Inhibition of apoptosome formation by suppression of Hsp90beta phosphorylation in tyrosine kinase-induced leukemias. Mol Cell Biol 28: 5494-5506, 2008

21. Hanahan D and Weinberg RA: The hallmarks of cancer. Cell 100 57-70, 2000.

22. Zimmermann KC and Green DR: How cells die: apoptosis pathways. J Allergy Clin Immunol 108 (Suppl 4): 99-103, 2001.

23. Chen F, Beezhold $\mathrm{K}$ and Castranova V: Tumor promoting or tumor suppressing of NF-kappa B, a matter of cell context dependency. Int Rev Immunol 27: 183-204, 2008.

24. Jobin C, Panja A, Hellerbrand C, et al: Inhibition of proinflammatory molecule production by adenovirus-mediated expression of a nuclear factor kappaB super-repressor in human intestinal epithelial cells. J Immunol 160: 410-418, 1998.

25. Hinz M, Loser P, Mathas S, Krappmann D, Dorken B and Scheidereit C: Constitutive NF-kappaB maintains high expression of a characteristic gene network, including CD40, CD86, and a set of antiapoptotic genes in Hodgkin/Reed-Sternberg cells, Blood 97: 2798-2807, 2001.

26. Huang S, Pettaway CA, Uehara H, Bucana CD and Fidler IJ: Blockade of NF-kappaB activity in human prostate cancer cells is associated with suppression of angiogenesis, invasion, and metastasis. Oncogene 20: 4188-4197, 2001.

27. Bian X, Opipari AW Jr, Ratanaproeksa AB, et al: Constitutively active NFkappa B is required for the survival of S-type neuroblastoma. J Biol Chem 277: 42144-42150, 2002. 